\title{
Awareness, attitude and preference of long-acting reversible contraceptives by Tanta University contraceptive clinic attendants
}

\section{Ayman Shehata Dawood*, Abdel-Ghaffar Said Dawood}

Department of Obstetrics and Gynecology, Tanta University, Tanta, Al Gharbia, Egypt

Received: 20 June 2017

Accepted: 19 July 2017

\section{*Correspondence:}

Dr. Ayman Shehata Dawood,

E-mail: ayman.dawood@med.tanta.edu.eg

Copyright: () the author(s), publisher and licensee Medip Academy. This is an open-access article distributed under the terms of the Creative Commons Attribution Non-Commercial License, which permits unrestricted non-commercial use, distribution, and reproduction in any medium, provided the original work is properly cited.

\section{ABSTRACT}

Background: Long Acting Reversible Contraceptives (LARC) had a very high efficacy in lowering unintended pregnancies and their poor health sequalae. Although their reported efficacy, these methods are not widely used among patient's due to non-awareness and faulty concepts linked to these methods.

Methods: This cross-sectional study was conducted to determine the degree of awareness, attitude and preference of LARC by attendants of Tanta University contraceptive clinic in the period from January 1, 2016 to December 31, 2016. All patients were counseled with thorough discussion about LARC methods. The following issues were determined: age, parity, mode of previous delivery, residence, medical diseases, socioeconomic state of family, type of LARC method used, how she know about this method and why she preferred that type.

Results: 391 women underwent this study with age range of 21-46 years, and BMI range of 20.46-31.87. LARC were preferred by $72.38 \%$ of patients and mainly IUDS $(52.94 \%)$ while other LARC methods were of very low awareness. Most patients take their knowledge from paramedical staffs $(49.87 \%)$. Occupation, education, residence and religion were not affecting patients' attitude and preference of one LARC over the other methods. Age was the most effective factor for determining whether to use LARC or not. Counseling revert a lot of faulty concepts and misbelieves about LARC.

Conclusions: LARC were not widespread among Tanta University attendants for contraception except for IUDs. Young patients had no motivations towards LARC due to a lot of faulty concepts that need a lot of work to be eradicated.

Keywords: Attitude, Family planning, LARC, Preference

\section{INTRODUCTION}

Population explosion is one of the major problems facing low resources countries and is a serious threat for economy and development. Family planning services are the cornerstone in the solution for rapid population growth. Moreover, these contraceptive methods allow for pregnancy spacing and hence improving women and children's health. ${ }^{1}$

According to World Health Organization (WHO), the estimated annual unintended pregnancies reached 80 million with 45 million pregnancies were terminated by unsafe abortion putting more and more hazards for maternal morbidity and even mortality. These unintended pregnancies occur when either no contraceptive method used, discontinued or inappropriately used. ${ }^{2,3}$

Many contraceptive methods are available and choosing one suitable method for each patient is a real challenge. Selection of one method and ability of the woman to take it appropriately are dependent on different factors; e.g. proper counselling by health care provider, methods awareness, socio-demographic characters, religious and personal attitudes. These all could hinder objectives behind family planning. ${ }^{4,5}$ LARC offer the opportunity to 
lower health hazards of unwanted pregnancies to planned safe conception. LARC methods offer long term, forgettable, and highly effective, contraceptive efficacy. LARC involve Intra-Uterine Device (IUD), Intra-Uterine System (IUS), Sub-dermal implants, and Injectable contraceptives; the old and new ones. These methods have a lot of misbelieves and hence their use is limited in low resources countries. ${ }^{6}$

The very little comprehensive researches about attitudes towards contraceptive methods in Egypt and especially LARC methods motivated us to conduct this comprehensive study to screen the awareness, attitude and practice towards these contraceptive methods. In this study, LARC methods were evaluated by applying a questionnaire for patients attending at Tanta University contraceptive clinic to show the experience and attitude towards these methods.

\section{METHODS}

\section{Study design and settings}

This study is a cross-sectional descriptive study, done at Tanta University contraceptive clinic in the period from January 1, 2016 to December 31, 2016.

\section{Patients}

All 391 patients attended at Tanta University contraceptive clinic and accepted to participate in this study were counseled and a questionnaire was applied about their socio-demographic characters, medical and obstetric histories, awareness about LARC, believes and misbelieves about LARC.

\section{Questionnaire was divided into 4 parts}

The first part determines socio-demographic data of enrolled patients including; age, parity, BMI, residence, educational level, and religion. The second part measures the awareness of LARC, attitude, popularity and methods by which knowledge of patients were built. The third part discusses the believes and misbelieves about LARC. The fourth part discusses the change of attitude after counseling of LARC and effect of provider on changing mind of clients.

\section{Statistical methods}

The data were analyzed using Software SPSS version18 and also descriptive statistics (frequency distribution, mean, SD) and correlations.

\section{RESULTS}

All included patient's demographic data were obtained where the mean age was $29.74 \pm 3.56$ years, the mean of parity was $3.44 \pm 1.2$ and the mean BMI was $24.07 \pm 3.87$. More than half of patients were occupied 204 (52.17\%) and most of them were from rural areas 259 (66.24\%). As regard educational level, most of patients were of low educational level $39.89 \%$ followed by high education level $128(32.74 \%)$ and the non-educated were 107 $(27.37 \%)$. The attendants were mostly Muslims 309 patients $(79.03 \%)$ and Christians about 82 patients (20.97\%) Table 1.

Table 1: Socio-demographic characters of enrolled patients.

\begin{tabular}{|lll|}
\hline & Range & Mean \pm SD \\
\hline Age (years) & $21-46$ & $29.74 \pm 3.56$ \\
\hline Parity & $1-6$ & $3.44 \pm 1.2$ \\
\hline BMI & $20.46-31.87$ & $24.07 \pm 3.87$ \\
\hline Occupation & & \\
\hline Occupied & $187(47.82 \%)$ & \\
\hline Non-occupied & $204(52.17 \%)$ \\
\hline Residence & & \\
\hline Urban & $132(33.76 \%)$ & \\
\hline Rural & $259(66.24 \%)$ & \\
\hline Educational level & \\
\hline Non-educated & $107(27.37 \%)$ & \\
\hline Low education & $156(39.89 \%)$ & \\
\hline High education & $128(32.74 \%)$ & \\
\hline Religion & \\
\hline Muslims & 309 & $79.03 \%$ \\
\hline Christians & 82 & $20.97 \%$ \\
\hline
\end{tabular}

Table 2: Awareness, attitude and misbelieves about LARC.

\begin{tabular}{|lll|}
\hline \multicolumn{2}{|l|}{ Number } & $\%$ \\
\hline Awareness about LARC & & \\
\hline Not at all & 144 & 36.83 \\
\hline Some awareness & 168 & 42.97 \\
\hline Full awareness & 79 & 20.20 \\
\hline Method of awareness & & \\
\hline Health care providers & 34 & 8.69 \\
\hline Para-medical team & 195 & 49.87 \\
\hline Non-medical personnel & 108 & 27.63 \\
\hline Social media & 54 & 13.81 \\
\hline Prior use of LARC & & \\
\hline Used before & 278 & 71.10 \\
\hline Not used before & 113 & 28.90 \\
\hline Misbelieves about LARC & & \\
\hline Permanent Amenorrhea & 311 & 79.54 \\
\hline Permanent infertility & 280 & 71.61 \\
\hline Irreversible weight gain & 301 & 76.98 \\
\hline Cancer pathogenesis & 45 & 11.50 \\
\hline Dyspareunia & 12 & 3.07 \\
\hline Osteoprosis & 12 & 3.07 \\
\hline
\end{tabular}

Questionnaire revealed that awareness about LARC was very low as 79 patients $(20.20 \%)$ only were fully aware about LARC methods while 168 patients (42.97\%) had some awareness especially about IUD and old injectables and the remaining 144 patients were totally non-aware 
about LARC as shown in Table 2. When we asked about the source of knowledge and awareness about LARC methods, we found that most patients $145(49.87 \%)$ obtained the knowledge from paramedical personnel, 108 patients $(27.63 \%)$ received awareness from non-medical personnel, 54 patients $(13.81 \%)$ received awareness from different social media while the least number of patients $34(8.69 \%)$ received awareness and knowledge from medical personnel denoting failure of counselling, communication or marketing of LARC Table 2.

Table 3: Correlation between preference of LARC and demographic data of enrolled patients.

\begin{tabular}{|c|c|c|c|c|c|c|c|}
\hline & IUD & IUS & Implants & $\begin{array}{l}\text { Old } \\
\text { Injectables }\end{array}$ & $\begin{array}{l}\text { New } \\
\text { Injectables }\end{array}$ & $\begin{array}{l}\text { Other } \\
\text { methods }\end{array}$ & Total \\
\hline \multicolumn{8}{|l|}{ Age } \\
\hline $21-30(96)$ & (9) $9.38 \%$ & (1) $1.04 \%$ & (1) $1.04 \%$ & $0 \%$ & $0 \%$ & (85) $81.6 \%$ & (96) $100 \%$ \\
\hline $30-40(233)$ & (183) $78.54 \%$ & (6) $2.76 \%$ & (5) $2.15 \%$ & (18) $7.73 \%$ & (3) $1.29 \%$ & (18) $7.37 \%$ & (233 $100 \%$ \\
\hline$>40(62)$ & (49) $79.03 \%$ & (2) $3.23 \%$ & (2) $3.23 \%$ & (4) $6.45 \%$ & $0 \%$ & (5) $8.06 \%$ & (62) $100 \%$ \\
\hline \multicolumn{8}{|l|}{ Parity } \\
\hline $1-3(177)$ & (86) $48.59 \%$ & (2) $1.13 \%$ & (5) $2.82 \%$ & (2) $1.13 \%$ & $0 \%$ & (82) $46.33 \%$ & (177) $100 \%$ \\
\hline$>3(214)$ & (155) $72.43 \%$ & (7) $3.27 \%$ & (3) $1.40 \%$ & (20) $9.35 \%$ & (3) $1.40 \%$ & (26) $12.15 \%$ & (214) $100 \%$ \\
\hline \multicolumn{8}{|l|}{ BMI } \\
\hline $20.46-25(291)$ & (173) $59.45 \%$ & (2) $0.69 \%$ & (6) $2.06 \%$ & (17) $5.84 \%$ & (3) $1.03 \%$ & (90) $30.93 \%$ & (291) $100 \%$ \\
\hline$>25(100)$ & (68) $68 \%$ & (7) $7 \%$ & (2) $2 \%$ & (5) $5 \%$ & $0 \%$ & (18) $18 \%$ & 100\% \\
\hline \multicolumn{8}{|l|}{ Occupation } \\
\hline Occupied (115) & (51) $44.35 \%$ & (2) $1.74 \%$ & (3) $2.61 \%$ & (20) $17.39 \%$ & (3) $2.61 \%$ & (36) $31.30 \%$ & (115) $100 \%$ \\
\hline Non-occupied (276) & (190) $68.84 \%$ & (7) $2.54 \%$ & (5) $1.81 \%$ & (2) $0.72 \%$ & $0 \%$ & (72) $26.09 \%$ & (276) $100 \%$ \\
\hline \multicolumn{8}{|l|}{ Residence } \\
\hline Rural (300) & (195) $65 \%$ & (2) $0.67 \%$ & $0 \%$ & (7) $2.33 \%$ & $0 \%$ & (96) $32 \%$ & (300) $100 \%$ \\
\hline Urban (91) & (46) $50.55 \%$ & (7) $7.69 \%$ & (8) $8.79 \%$ & (15) $16.48 \%$ & (3) $3.30 \%$ & (12) $13.19 \%$ & (91) $100 \%$ \\
\hline \multicolumn{8}{|l|}{ Educational level } \\
\hline Non-educated (92) & (57) $61.96 \%$ & $0 \%$ & $0 \%$ & (9) $9.78 \%$ & $0 \%$ & (26) $28.26 \%$ & (92) $100 \%$ \\
\hline Low education (206) & (157) $76.21 \%$ & $0 \%$ & (2) $0.97 \%$ & (5) $2.43 \%$ & $0 \%$ & (42) $20.39 \%$ & (206) $100 \%$ \\
\hline High education (93) & (27) $29.03 \%$ & (9) $9.68 \%$ & (6) $6.45 \%$ & (8) $8.60 \%$ & (3) $3.23 \%$ & (40) $43.01 \%$ & (93) $100 \%$ \\
\hline \multicolumn{8}{|l|}{ Religion } \\
\hline Muslims (347) & (229) $65.99 \%$ & (7) $2.02 \%$ & (7) $2.02 \%$ & (16) $4.61 \%$ & (3) $0.86 \%$ & (85) $24.50 \%$ & (347) $100 \%$ \\
\hline Christians (44) & (12) $27.27 \%$ & (2) $4.55 \%$ & (1) $2.27 \%$ & (6) $13.64 \%$ & $0 \%$ & (23) $52.27 \%$ & (44) $100 \%$ \\
\hline
\end{tabular}

The most popular method which had the highest awareness was not a problem as most patients receive awareness from paramedical and non-medical personnel. The method of LARC which was widely known at Tanta University contraceptive clinic was the IUD (52.94\%), followed by old injectables $(33.76 \%)$, Implants was in third position $(8.95 \%)$. The LARC methods of lowest awareness and popularity were IUS $(1.79 \%)$ and the new injectables (SAYANA®) which was popular by $2.56 \%$ Figure 1.

The questionnaire involved also the number and percentage of patients who had previous use of LARC, where $278(71.10 \%)$ used LARC previously and 113 $(28.90 \%)$ didn't use LARC before. Astonishing results were obtained when we asked about misbelieves taken about LARC methods, where 311 patients (79.54\%) were convinced that LARC methods are linked with permanent amenorrhea, 301 patients $(76.98 \%)$ had wrong believes that LARC cause irreversible weight gain, 280 patients $(71.61 \%)$ had wrong believes that these methods cause irreversible infertility, relation to cancer pathogenesis was found in 45 patients $(11.50 \%)$, osteoporosis and dyspareunia were found in 12 patients $(3.07 \%)$ Table 2 .

Correlations between LARC preference and sociodemographic data were declared in Table 3 where each demographic parameter was correlated to each LARC method. LARC were preferred to be used by (283/391) $72.38 \%$ while $(108 / 391)$ prefer to use other methods. LARC were preferred in ages $>30$ years while young patients $<30$ years prefer other methods. According to BMI, obese patients with BMI>25 prefer IUD and refuse injectables due to misbelieves of increase in weight and blood pressure.

According to occupation, $68.84 \%$ of the non-occupied patients prefer IUD and $26.09 \%$ prefer other methods while $44.35 \%$ occupied patients prefer IUD and $31.30 \%$ prefer other methods. IUS and SAYANA are more used in urban patients than in rural areas. According to Educational level highly educated patients were motivated towards IUS and SAYANA and prefer some other methods. There was no difference between Muslims and Christians in preference of LARC methods Table 3. 


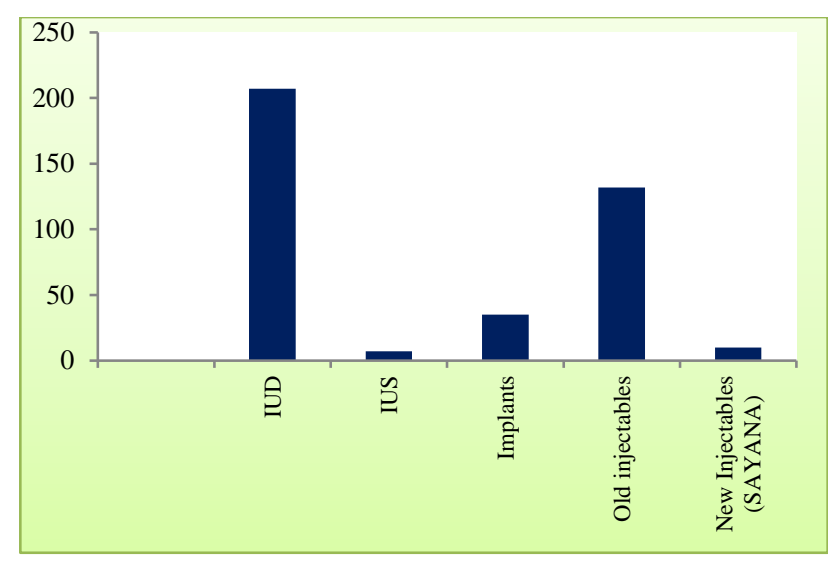

Figure 1: Popularity of LARC at Tanta University contraceptive clinic.

After appropriate counselling, many patients changed their minds and misbelieves about LARC methods. Before counselling only 103/391 patients (26.34\%) were satisfied and accepting LARC but after counselling 283/391 patients $(72.38 \%$ ) become convinced by LARC after declaration of all misbelieves Figure 2.

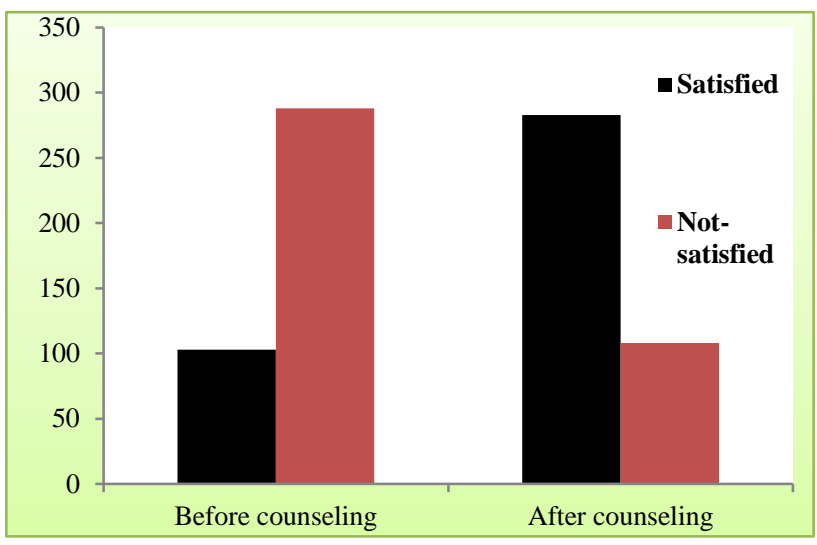

Figure 2: Satisfaction and Acceptance of LARC methods before and after appropriate counselling and declaring misbelieves.

\section{DISCUSSION}

Family planning services are not considered only as the key to the population growth and improving women health, but also considered the fundamental human right. Long acting reversible contraceptives (LARC) are highly effective methods of contraception compared to other methods. These methods are less widely used in developing countries remaining unknown soldiers. These methods reduce unintended pregnancies and their linked morbidities and probable mortality. ${ }^{7}$ Attitude towards contraceptive methods is affected by many factors as socio-demographic criteria of a particular population, religious, economic and health issues. Knowledge of particular population about contraceptive methods is also affected by educational level, adherence to medical services, patient decision and sometimes husband or family opinion..$^{8-10}$

Beekle et al conducted a study to determine awareness and determinants of family planning practice and they concluded that acceptance of contraceptive methods could not be adequate by knowledge and access to the services alone. This is more evident in developing countries, where old traditions and social constraints affect women knowledge and awareness about family planning acceptance. ${ }^{11}$

An American study stated that economic factors and access to the health care are important determinant factors for contraceptive method selection but it has been proven that knowledge, attitude and cultural values have higher and predominant effect. ${ }^{12}$

In the current study IUD was the most popular method of LARC widely known at Tanta University contraceptive clinic $(52.94 \%)$, followed by old injectables $(33.76 \%)$, Implants was in third position (8.95\%). The LARC methods of lowest awareness and popularity were IUS $(1.79 \%)$ and the new injectables (SAYANA®) which was popular by $2.56 \%$. Figure 1 Unequal use and acceptance of contraceptive methods everywhere are affected by, social and cultural environment leading to dominance of one method or more over others. ${ }^{13}$

In the current study, misbelieves about LARC were as follow permanent amenorrhea (79.54\%), permanent infertility $(71.61 \%)$, irreversible weight gain $(76.98 \%)$, cancer pathogenesis $(11.50 \%)$, osteoporosis $(3.07 \%)$ and dry vagina causing dyspareunia (3.07\%). Table 2 These results were supported by Ramachandran et al (2006) who found some attitudes and misbelieves in human being (such as superstition, delusions, and prejudices) which should be identified as these are away from the reality and had deleterious effects on attitude towards contraceptive methods. ${ }^{14}$

In the current study, counseling reverted opinions and attitudes of the patients who were not satisfied with LARC $(26.34 \%)$ to be more convinced and satisfied after declaration of false concepts and misbelieves $(72.38 \%)$. Figure 2.

Contraceptive consulting is more than proving information or answering to the questions of the clients; but health staff should explore and modify their attitudes and beliefs in this area. Counseling is crucial to change patients' minds, attitude towards selection of contraceptive methods. Failure of counseling may be due to either provider or patient failure. ${ }^{15,16}$ In the current study we found that IUS, new injectables (SAYANA), and implants the lowest methods as regard awareness and this refers to poor counseling prior contraception Figure 1. Another study explained why LARC methods are not popular except for IUDs, this study proposed that barriers to widespread use of LARC methods are persistent and 
include educational, access to health services, and cost. ${ }^{6}$ On the other hand an interesting study surveyed Obstetrician-Gynecologists knowledge, training, practice and beliefs regarding LARC methods. That study found that almost all obstetrician-gynecologists reported providing IUDs $(95.8 \%)$ and concluded that barriers to LARC widespread could be reduced if more obstetriciangynecologists received implant training and provided same-day IUD insertion. ${ }^{17}$

In the present study LARC use was lower than expected in the age groups experiencing the highest number of unwanted pregnancies where we found that $81.6 \%$ of young patients $<30$ years prefer other methods. Table 3 Similarly Kopp Kallner et al found that young women had lower derives to choose LARC methods increasing the rate of unwanted pregnancies. ${ }^{18}$ Another study done in Uganda found that injections (Type of LARC) were the predominantly used method among both the young and the older women. ${ }^{19}$

Occupation, residence, religion and educational level in the current study, have non-significant impacts on the preference and attitude of patients towards LARC. The only positive effects of these factors were evident in the awareness and socio-economic condition for selection of costly LARC such as IUS and SAYANA. Table 3 Other studies proved difference between occupied and nonoccupied women in selection of contraceptive methods, residence, religious, cultural effects, and educational level. ${ }^{20-23}$

\section{CONCLUSION}

Awareness about LARC was not sufficient for their actual use at Tanta University Contraceptive Clinic and new ways of motivating people to adopt and sustain these types of family planning methods should be considered. Stress on the use of LARC methods among young women is firmly recommended by proper counseling to eradicate faulty concepts about these methods.

\section{ACKNOWLEDGMENTS}

Authors would like to thank all residents of Obstetrics and Gynecology at Tanta University who recruited patients, applied the questionnaire, collected data, and contacted required patients.

\section{Funding: No funding sources}

Conflict of interest: None declared

Ethical approval: The study was approved by the Institutional Ethics Committee

\section{REFERENCES}

1. United Nations Population Fund: State of the world population 2004. The Cairo consensus at ten: population, reproductive health and the global effort to end poverty. In.: UNFPA, New York; 2004.
2. World Health Organization. Selected practice recommendations for contraceptive use. 2nd ed.; 2004 Available at http://whqlibdoc.who.int/publications/2004/9241562 846.pdf [Accessed 2009 Dec 8].

3. World Health Organization. Medical eligibility criteria for contraceptive use. 3rd ed.; 2004. Available http://whqlibdoc.who.int/publications/2004/9241562 668.pdf.

4. Jahan U, Verma K, Gupta S, Gupta R, Mahour S, Kirti $\mathrm{N}$ et al. Awareness, attitude and practice of family planning methods in a tertiary care hospital, Uttar Pradesh, India. Int J Reprod Contracept Obstet Gynecol. 2017;6(2):500-6.

5. Ochako R, Mbondo $\mathrm{M}$, Aloo S, Kaimenyi S, Thompson R, Temmerman $\mathrm{M}$ et al. Barriers to modern contraceptive methods uptake among young women in Kenya: a qualitative study. BMC Public Health. 2015;15(1):118.

6. Parks C, Peipert JF. Eliminating health disparities in unintended pregnancy with long-acting reversible contraception (LARC). American J Obstet Gynecol. 2016;214(6):681-8.

7. Belfield T. Principles of contraceptive care: choice, acceptability and access. Best Pract Res Clin Obstet Gynecol. 2009;23(2):177-85.

8. Ehsanpour S, Mohammadifard M, Shahidi S, Nekouyi NS. A comparative study on attitude of contraceptive methods users towards common contraceptive methods. Iran J Nurs Midwifery Res. 2010;15(Suppl1):363-70.

9. Hooper DJ. Attitudes, awareness, compliance and preferences among hormonal contraception users. Clinical Drug Invest. 2010;30(11):749-63.

10. Lamidi EO. State variations in women's socioeconomic status and use of modern contraceptives in Nigeria. PloS one. 2015;10(8):e0135172.

11. Beekle AT, McCabe C. Awareness and determinants of family planning practice in Jimma, Ethiopia. Int Nurs Rev. 2006;53(4):269-76.

12. Sangi-Haghpeykar H, Ali N, Posner S, Poindexter AN. Disparities in contraceptive knowledge, attitude and use between Hispanic and non-Hispanic whites. Contraception. 2006;74(2):125-32.

13. Sereshti M, Delaram M, Rafian M. Incidence and View Point of pregnant Women about Factors Associated with Unwanted pregnancy in Shahrekord. Scientific J Hamadan Nurs Midwif Facult. 2005;13(2):8-14.

14. Ramachandran L, Dharmalingam T. A textbook of health education. In: Shafiei F, Azargashb E, translators. Tehran: University of Tehran; 2006.

15. Ozgoli G, Ahmadi M, Goli Sh, Akbarzadeh Baghban A. Comparison of knowledge, attitude and other related factors to sterilization between sterilization method users and contraceptive methods users in Hamedan city in 2003. J Reprod Infertility. 2004;5(3):259-67. 
16. Dawood AS. Counseling Prior Contraception: Is It a Provider Failure or Patient Failure? J Contracept Stud. 2017;2:1.

17. Luchowski AT, Anderson BL, Power ML, Raglan GB, Espey E, Schulkin J. Obstetrician-Gynecologists and contraception: long-acting reversible contraception practices and education. Contraception. 2014;89(6):578-83.

18. Kopp Kallner H, Thunell L, Brynhildsen J, Lindeberg M, Gemzell Danielsson K. Use of contraception and attitudes towards contraceptive use in swedish women - a nationwide survey. PLoS One. 2015;10(5):e0125990.

19. Asiimwe JB, Ndugga P, Mushomi J, Ntozi JP. Factors associated with modern contraceptive use among young and older women in Uganda; a comparative analysis. BMC Public Health. 2014;14(1):926.

20. Islam AZ, Mondal MN, Khatun ML, Rahman MM, Islam MR, Mostofa MG et al. Prevalence and determinants of contraceptive use among employed and unemployed women in Bangladesh. Int J MCH AIDS. 2016;5(2):92.

21. Padhy S, Nayak R, Tripathy RM. Study of sociodemographic profile and contraceptive use among married women attending an Urban Health Centre, Berhampur. Int J Medic Res Rev. 201631;4(12).

22. Srikanthan A, Reid RL. Religious and cultural influences on contraception. J Obstet Gynecol Can. 2008;30(2):129-37.

23. Koch E, Calhoun B, Aracena P, Gatica S, Bravo M. Women's education level, contraceptive use and maternal mortality estimates. Public Health. 2014;128(4):384-7.

Cite this article as: Dawood AS, Dawood AGS Awareness, attitude and preference of long-acting reversible contraceptives by Tanta University contraceptive clinic attendants. Int J Reprod Contracept Obstet Gynecol 2017;6:3725-30. 